\title{
BEHAVIOUR OF CONCRETE BEAMS REINFORCED WITH GLASS FIBRE REINFORCED POLYMER FLATS
}

\author{
G. Jyothi Kumari ${ }^{1}$, P. Jagannadha Rao ${ }^{2}$, M. V. Seshagiri Rao ${ }^{3}$ \\ ${ }^{I}$ Asst Professor, Dept. of Civil Engg, GITAM University, Hyderabad, India \\ ${ }^{2}$ Professor \& Head, Dept. of Civil Engg, ACE college of Engg and Technology, Hyderabad, India \\ ${ }^{3}$ Professor Dept. of Civil Engg, Jawaharlal Nehru Technology University Hyderabad, India, \\ jyothineelapu@gmail.com
}

\begin{abstract}
Concrete is very strong in compression but it is extremely weak in tension. To resist the tensile stress, steel reinforcement is provided in concrete. Reinforcement corrosion and structural deterioration in reinforced concrete structures are common, and prompted many researchers to seek alternative materials and rehabilitation techniques. One such material that has been offered as an alternative to mild steel reinforcement is Glass Fibre Reinforced Polymer (GFRP) bars and flats. For the repair and strengthening of structural concrete members, strengthening with Glass Fibre Reinforced Polymer (GFRP) plates is an excellent option. The present work is to study the behavior of Shear resistance of the silica coated GFRP stirrups in the shear test zone. A series of studies were conducted using silica coated GFRP stirrups in shear zone. It is observed that beams with silica coated GFRP flats shear reinforcement have shown failure at higher loads than the theoretical failure loads. Further it is observed that GFRP flats as shear reinforcement exhibit fairly good ductility. Detailed experimental investigations, results and conclusions are given in the page that follows.
\end{abstract}

\section{INTRODUCTION}

A variety of new materials in the field of concrete technology have been developed during the past three decades with the ongoing demand of construction industries to meet the functional, strength, economical and durability requirements. Though concrete has high compressive strength and is the most widely used construction material it suffers from the following three disadvantages.

a) Weak in tension.

b) Highly porous.

c) Susceptible to chemical and environmental attack.

The above deficiencies of plain concrete are over-come in the new materials (special cements and concrete composites) developed over the past two or three decades. These special cement concrete composites have unique characteristics, which make them highly susceptible to any given application or environment. FRC is one such material with wide range of applications.

Fibre reinforced concrete is relatively a new composite material in which concrete is reinforced with short discrete, discontinuous and uniformly distributed fibres so as to improve many engineering properties such as flexural strength, shear strength, resistance to fatigue, impact, thermal shock or spalling. Fibre is a piece of reinforcing material usually described by its aspect ratio which is defined as the ratio of length of fibre to its equivalent diameter.

\section{MATERIALS OF GFRP CONCRETE}

Cement: Ordinary Portland Cement (OPC) of 53 grade confirming to IS: 8112 can be used.

Aggregate: The coarse aggregate chosen for GFRC is typically angular in shape, is well graded, and smaller in maximum size that suited for conventional concrete.

Water: Locally available potable water, which is pure and free from harmful impurities such as oil, alkali, acid etc, is used.

Gfrp Bars And Flats: Silica coated GFRP bars of diameter $6 \mathrm{~mm}$ with Fiber Resin ratio 7:3 with tensile strength of 380 Mpa are used.

Mild Steel Bars: Mild steel bars of diameter $6 \mathrm{~mm}$ and yield strength of $250 \mathrm{Mpa}$ were used for casting of control specimens for comparative study.

Hysd Bars: HYSD bars of diameter $8 \mathrm{~mm}$ were used for casting of specimens.

Polyester Resin: Polyester resin was used to prepare GFRP laminates. It consists of $60 \%$ resin, 30\% hardener and $10 \%$ accelerator. 
Nito Bond: Nito bond made by Fosrock was used as surface coating on the plain GFRP rebar's to improve the bond between concrete and rebars.

\section{EXPERIMENTAL WORK}

Cement: In the present investigation ordinary Portland cement IS type cement of 53 Grade (Ultra Tech) is used. The cement thus produced was tested for physical properties in accordance with IS 4031.

Fine Aggregate: Fine aggregate is natural sand obtained from local market. The physical properties like specific gravity, bulk density, gradation fineness modulus were determined in accordance with IS 2386.

Coarse Aggregate: The crushed coarse aggregate of $12 \mathrm{~mm}$ maximum size angular obtained from the local crushing plant, at Hyderabad is used in the present study. The physical properties of the coarse aggregate like specific gravity, bulk density, gradation and fineness modulus were found in accordance with IS 2386.

Water: This is the least expensive but most important ingredient in concrete. The water, which is used for making concrete, should be clean and free from harmful impurities such as oil, alkali, and acid e.t.c., in general, the water fit for drinking, should be used for making concrete.

Concrete Mix: A concrete mix of 1:1.5:3 with a water cement ratio of 0.52 was used for the investigation.

In the process of mixing, the material is weighed with their proportions exactly and then the materials are stacked on a water tight platform. The materials are thoroughly mixed in their dry condition before water is added. The prepared mix was immediately used for testing the workability of fresh mix Standard moulds made of cast Iron were used for casting cubes and beams. The specimens were cast and cured for 28 days in potable water at ambient temperature as per standards. After casting, the moulded specimens were stored in the laboratory at room temperature for 24 hours. After these periods the specimens are removed from the moulds and the specimens were cured for 28 days in the present investigation work.

Table 1 Material Quantities:

\begin{tabular}{|c|c|c|}
\hline S No. & Material & Quantity $\left(\mathbf{k g} / \mathbf{m}^{\mathbf{3}}\right)$ \\
\hline 1 & Cement & 380 \\
\hline 2 & Fine Aggregate & 624.5 \\
\hline 3 & Coarse Aggregate & 1131.5 \\
\hline 4 & Water & 197 \\
\hline
\end{tabular}

Compressive Strength: In the present investigation the size of $150 \times 150 \times 150 \mathrm{~mm}$ are used. According to BIS 1881: part 116:1983, the load on the cube should be applied at a constant rate of stress equal to 0.2 to $0.4 \mathrm{Mpa} / \mathrm{sec}$

\subsection{Experimental Program}

Shear resistance of the silica coated GFRP stirrups in the shear test zone was studied in the experimentation

The experiments were conducted on three series of beams A, $\mathrm{B}$, and C with GFRP flats of size $25 \times 2.5 \mathrm{~mm}$ as shear reinforcement. The dimensions of all the beams are $75 \mathrm{X} 150$ $\mathrm{X} 1200 \mathrm{~mm}$ overall and the effective length being 1000mm.The A series of beams comprise five numbers of control specimens using three numbers of $8 \mathrm{~mm} \emptyset$ HYSD bars as flexural reinforcement. To examine the capability of concrete in resisting shear, shear reinforcement was not provided in the shear test zone.

Under B series five numbers of beams were cast using flexural reinforcement of three numbers of $8 \mathrm{~mm} \varnothing$ HYSD bars. In the shear test zone two legged $25 X 2.5 \mathrm{~mm}$ sized silica coated GFRP flats at $87 \mathrm{~mm}$ spacing was arranged as shear reinforcement.

In $\mathrm{C}$ series five numbers of beams were cast using flexural reinforcement of three numbers of $8 \mathrm{~mm} \varnothing$ HYSD bars. In the shear test zone two legged $25 \mathrm{X} 2.5 \mathrm{~mm}$ size silica coated GFRP flats at $110 \mathrm{~mm}$ spacing was arranged as shear reinforcement. To arrest the failure in the non test zone shear reinforcement of two legged mild steel $6 \mathrm{~mm} \varnothing$ stirrups at $50 \mathrm{~mm}$ centre to centre was arranged in all the beams. In the bending zone shear reinforcement was not provided as tests were conducted in pure bending duly arranging the two point loading.

Testing Of Specimens: Tensile tests of GFRP rebars were tested on the tension testing machine of 5 ton capacity. Double shear test on $10 \mathrm{~mm}$ dia GFRP rebar's were conducted on Universal Testing Machine.10mm dia GFRP rebars were tested for impact strength on Izod Impact Testing Machine. Concrete cubes and cylinders were tested on 3000k capacity Digital Compression Testing Machine for their compressive and split tensile strengths respectively. The prisms were tested on Flexure Testing Machine for modulus of rupture. The test beams were tested for shear under static two point loading.

\section{EXPERIMENTAL OBSERVATIONS}

As mentioned in the table 2 the physical properties of the ordinary Portland cement use in the present investigation and they confirm to I.S Specifications. The 28 days compressive strength is $54.7 \mathrm{Mpa}$. 
Table 2 Physical properties of cement

\begin{tabular}{|l|l|}
\hline Specific Gravity of Cement & 3.15 \\
\hline Initial Setting time & $42 \mathrm{~min}$ \\
\hline Final setting time & $10 \mathrm{Hrs}$ \\
\hline Normal Consistency & $30 \%$ \\
\hline Compressive Strength & $54.7 \mathrm{~N} / \mathrm{mm} 2$ \\
\hline
\end{tabular}

\subsection{Properties Of Aggregate}

Table 3 Physical properties of coarse aggregate (12 $\mathrm{mm}$ )

\begin{tabular}{|l|l|}
\hline Property & Value \\
\hline Fineness modulus & 6.2 \\
\hline Specific gravity & 2.67 \\
\hline Bulk density $\left(\mathrm{kg} / \mathrm{m}^{3}\right) \quad$ - Loose & 1380 \\
\hline Bulk density (kg/m $\mathrm{m}^{3)}$ - Dense & 1530 \\
\hline Flakiness index & $2.36 \%$ \\
\hline Elongation index & $12.6 \%$ \\
\hline Angularity index & $38.7 \%$ \\
\hline
\end{tabular}

\section{Physical properties of fine aggregate:}

Fineness modulus was found based on sieve analysis results for fine aggregate. Weight of the sample taken was 1000 grams.

Fineness modulus of fine aggregate $\quad=\quad 3.3$ Specific gravity

$=2.62$

From the above sieve analysis we can say fine aggregate confirms to Zone II grading of IS.
Mix Proportions: In the present investigation mix proportioning is done using BIS method for M25 grade concrete. The resulting mixes are modified after doing corrections and trials are done at laboratory to achieve desired mix proportion. Test specimens of cubes and cylinders were casted.

Fresh Concrete: The results of various tests done for evaluating various properties of concrete. No segregation was observed in any of the mix and the viscosity of the mix is enough to carry the coarse aggregate particles and the mix remained homogenous throughout.

The slump flow, compaction factor tests were done and the values are with in limits.

\section{COMPRESSIVE STRENGTH}

The compressive strength of the cubes are satisfying the characteristic compressive strengths expected.

Table 4: Ratio of Mix proportions by weight for M25 Mix

\begin{tabular}{|c|r|c|c|c|}
\hline Mix & Cement & F.A & C.A & W/c \\
\hline M25 & 1 & 1.64 & 3.97 & 0.52 \\
\hline
\end{tabular}

Table 5: Compressive Strength

\begin{tabular}{|c|c|c|c|}
\hline S .No & Mix & Day 7 & Day 28 \\
\hline 1 & M25 & 1 & 28.6 \\
\hline
\end{tabular}

Table 6: Tensile strength

\begin{tabular}{|c|c|c|}
\hline Sno & Material & Tensile strength(MPa) \\
\hline 1 & GFRP bar & 300 \\
\hline 2 & Mild steel bar & 250 \\
\hline
\end{tabular}

2 Nos. $6 \mathrm{~mm}$ dia. MS Hanger

bars

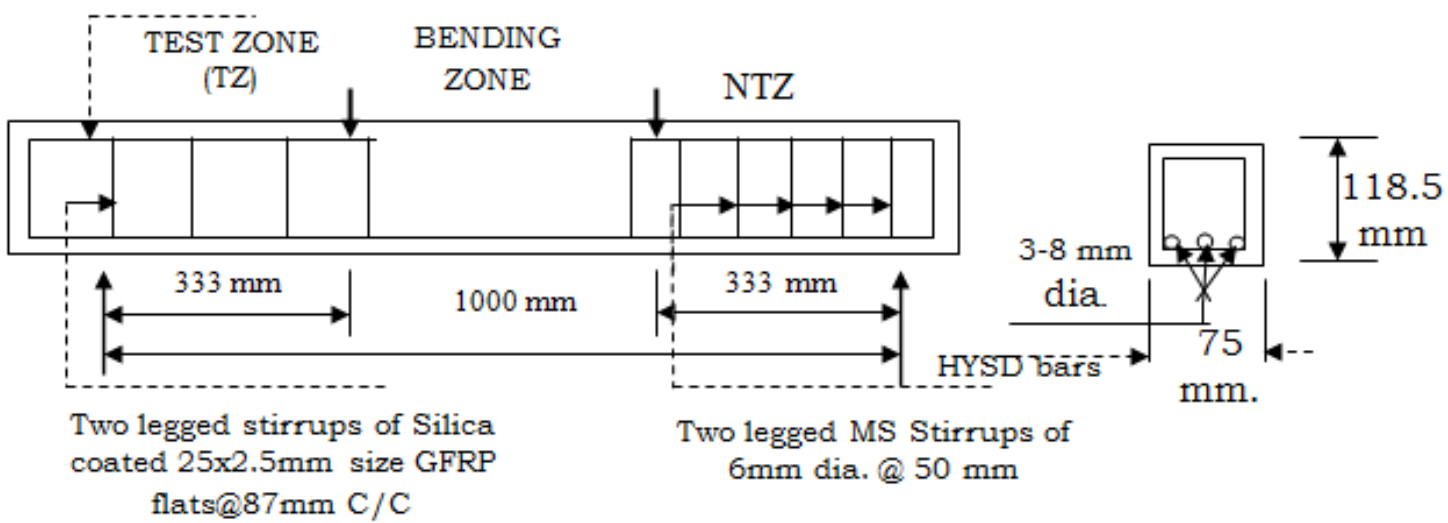

Fig.1: Details of Beams of Series A 


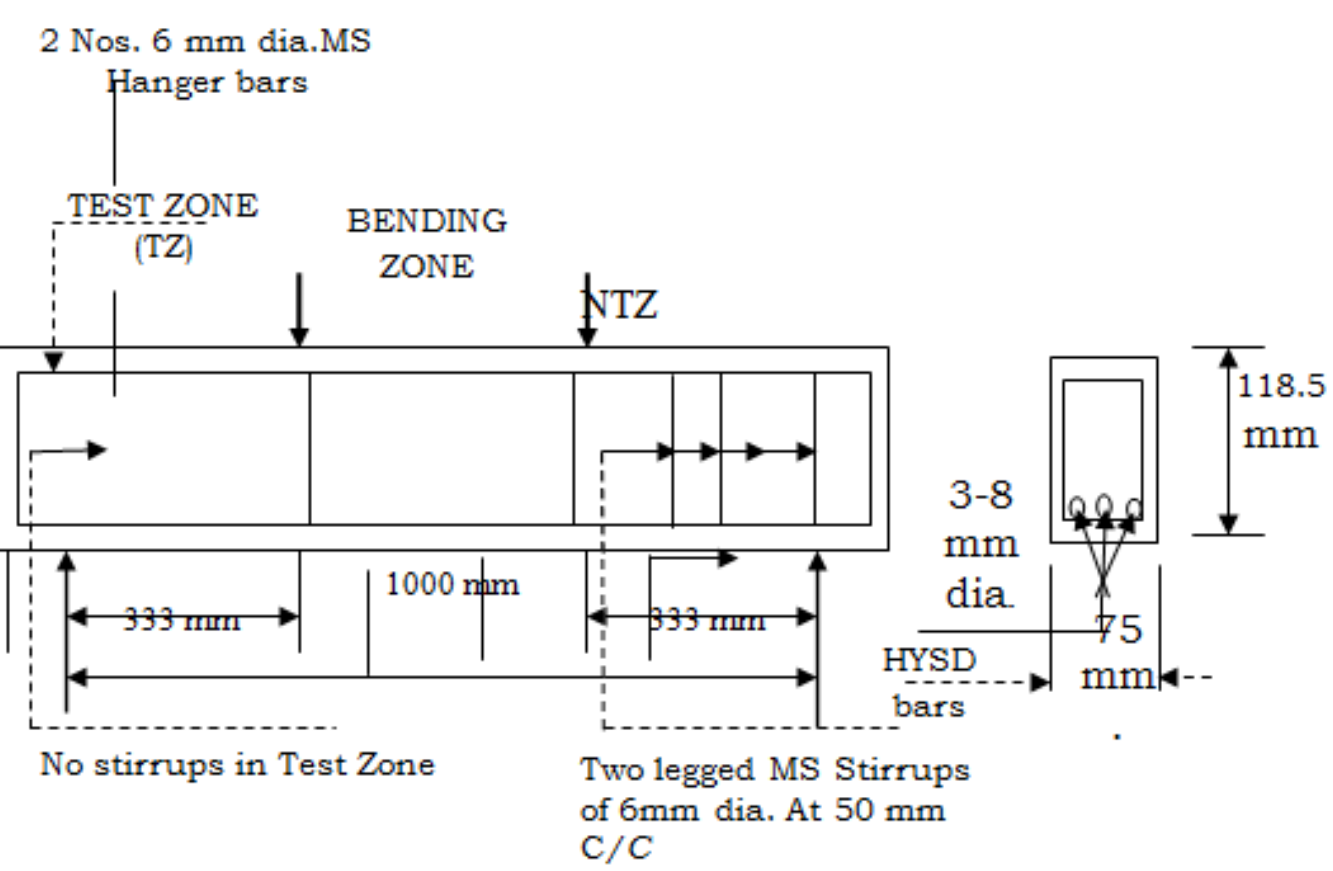

Fig.2: Details of Beams of Series B

2 Nos. $6 \mathrm{~mm}$ dia.MS

Hanger bars

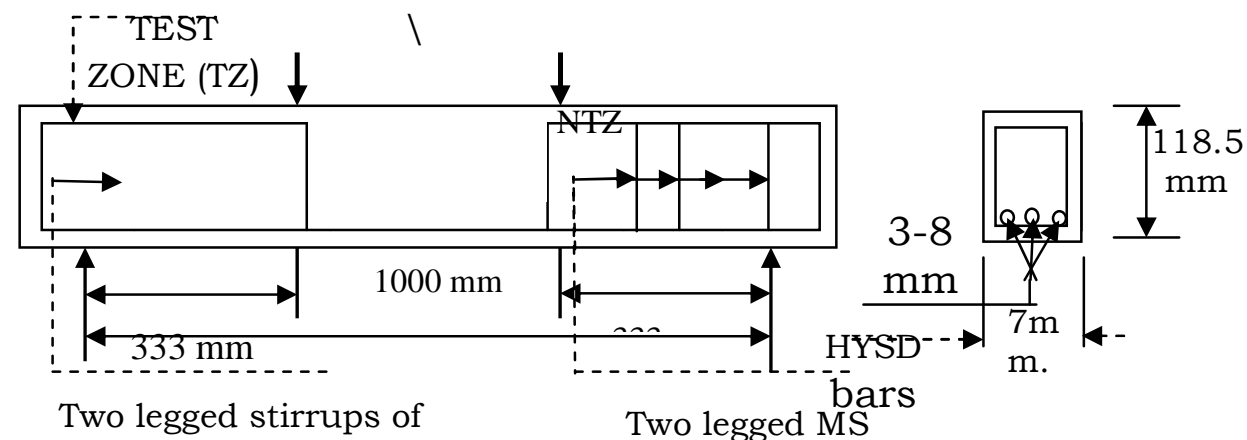

Silica coated $25 \times 2.5 \mathrm{~mm}$

Stirrups of $6 \mathrm{~mm}$ dia.

size GFRP flats@110mm @ @ $50 \mathrm{~mm} \mathrm{C} / \mathrm{C}$

$$
\mathrm{C} / \mathrm{C}
$$

Fig.3: Details of Beams of Series C

Table .7: Details of Test Beam showing average values of shear force and deflections

\begin{tabular}{|c|l|l|l|l|l|}
\hline $\mathbf{C S}$ & & $\mathbf{S - 8 7}$ & & $\mathbf{S - 1 1 0}$ & \\
\hline $\mathbf{D E F}(\mathbf{m m})$ & $\mathbf{S F}(\mathbf{k N})$ & $\mathbf{D E F}(\mathbf{m m})$ & $\mathbf{S F}(\mathbf{k N})$ & $\mathbf{D E F}(\mathbf{m m})$ & $\mathbf{S F}(\mathbf{k N})$ \\
\hline 0.00 & 0.00 & 0.00 & 0.00 & 0.00 & 0.00 \\
\hline 0.35 & 3.35 & 0.50 & 8.35 & 0.54 & 6.96 \\
\hline 0.70 & 5.58 & 1.50 & 15.81 & 1.08 & 11.61 \\
\hline 1.40 & 7.14 & 2.00 & 16.45 & 2.15 & 14.86 \\
\hline 2.10 & 7.81 & 4.00 & 19.40 & 3.23 & 16.25 \\
\hline 2.80 & 8.48 & 6.00 & 21.85 & 4.31 & 17.64 \\
\hline
\end{tabular}




\begin{tabular}{|l|l|l|l|l|l|}
3.50 & 9.15 & 8.00 & 23.64 & 5.38 & 19.04 \\
\hline 4.20 & 9.82 & 10.00 & 24.67 & 6.46 & 20.43 \\
\hline 4.90 & 10.49 & 12.00 & 25.83 & 7.54 & 21.82 \\
\hline 9.10 & 12.50 & 14.00 & 26.99 & 14.00 & 26.00 \\
\hline & & 16.00 & 27.50 & & \\
\hline
\end{tabular}

Note : CS - control specimen (no stirrups in shear test zone) S-87-Beams with two legged 25x2.5mm GFRP flats@87mm c/c in shear test zone.S-110-Beams with two legged 25x2.5mm GFRP flats@110mm c/c in shear test zone

Table 8: Test Results of beams showing ratio of Ultimate Shear to Shear at first crack

\begin{tabular}{|c|c|c|c|c|}
\hline Beam ID Name & Shear at First Crack & Ultimate Shear & $\begin{array}{c}\text { Ultimate Shear /Shear } \\
\text { at First Crack }\end{array}$ & Remarks \\
\hline A1 & 9.35 & 13.09 & 1.40 & \multirow{2}{P}{$=1.7$} \\
And \\
a/d $=0.33$ \\
A2 & 7.65 & 12.40 & 1.62 \\
\hline A3 & 7.76 & 11.88 & 1.53 \\
\hline A4 & 8.16 & 11.75 & 1.44 \\
\hline B5 & 8.86 & 13.38 & 1.51 \\
\hline B2 & 23.87 & 28.88 & 1.21 \\
\hline B3 & 19.86 & 26.22 & 1.32 \\
\hline B4 & 19.03 & 27.40 & 1.44 \\
\hline B5 & 22.00 & 29.70 & 1.12 \\
\hline C1 & 19.02 & 25.30 & 1.33 \\
\hline C3 & 22.99 & 27.82 & 1.21 \\
\hline C4 & 18.91 & 24.96 & 1.32 \\
\hline C5 & 20.88 & 24.22 & 1.16 \\
\hline
\end{tabular}

Table 9. Comparison of Test Results of with the calculated Shear strength values

\begin{tabular}{|c|c|c|c|c|c|c|}
\hline Beam ID Name & $\frac{a}{d}$ & $p$ & $f_{c k}$ & $\begin{array}{l}\text { Theoretical } \\
\text { Ultimate } \\
\operatorname{Shear}\left(V_{t h}\right)\end{array}$ & $\begin{array}{l}\text { Experimental } \\
\text { Ultimate } \\
\text { Shear }\left(V_{a c t}\right)\end{array}$ & $\frac{V_{a c t}}{V_{t h}}$ \\
\hline A & 2.81 & 1.7 & 27 & 10.19 & 12.50 & 1.23 \\
\hline B & 2.81 & 1.7 & 27 & 16.94 & 27.50 & 1.62 \\
\hline $\mathrm{C}$ & 2.81 & 1.7 & 27 & 16.94 & 26.00 & 1.57 \\
\hline
\end{tabular}




\section{6: DISCUSSION OF TEST RESULTS}

\subsection{Tests on GFRP Bars and Flats with and without Silica Coating:}

Tensile strength tests were conducted on plain and silica coated GFRP bars of $10 \mathrm{~mm} \emptyset$ and $6 \mathrm{~mm} \emptyset$, to understand the tensile behavior and to determine the modulus of elasticity. The glass fiber and resin proportion of 7:3 was used to manufacture the GFRP bars. The average tensile strength of $10 \mathrm{~mm}$ dia. GFRP bars was found to be $380 \mathrm{Mpa}$, for both plain and silica coated bars. The tensile strength of $6 \mathrm{~mm}$ bars was found to be 416 Mpa for silica coated and plain bars similar to that of pre-stressing strands. The average tensile strength of $25 \mathrm{mmX} 2.5 \mathrm{~mm}$ size GFRP flats was found to be $370 \mathrm{Mpa}$, for both plain and silica coated bars. It is observed that the silica coating did not influence the tensile strength of the bars significantly. The failure pattern for plain $10 \mathrm{~mm}$ and $6 \mathrm{~mm}$ bars was brittle and associated with splintering of glass fibers. Similar behavior was observed in the case of silica-coated bars of same diameter.

\subsection{Shear Tests:}

A total number of fifteen beams were tested in shear in this phase. For control specimens with no shear reinforcement the first crack has occurred at $8.36 \mathrm{KN}$ and failed at an ultimate shear of 12.5 $\mathrm{KN}$ and the ratio of ultimate shear to shear at first crack being 1.5. For beams with shear reinforcement using silica coated two legged $25 \mathrm{~mm} \times 2.5 \mathrm{~mm}$ size GFRP flats at $110 \mathrm{~mm} \mathrm{c} / \mathrm{c}$ the first crack has occurred at $20.52 \mathrm{KN}$ and failed at an ultimate shear of $26 \mathrm{KN}$ and the ratio of ultimate shear to shear at first crack being 1.27 , where as for beams with shear reinforcement using silica coated two legged $25 \mathrm{~mm} \times 2.5 \mathrm{~mm}$ size GFRP flats at $87 \mathrm{~mm}$ $\mathrm{c} / \mathrm{c}$ the first crack has occurred at $20.76 \mathrm{KN}$ and failed at an ultimate shear of $27.50 \mathrm{KN}$ and the ratio of ultimate shear to shear at first crack being 1.33 .It was observed that there is marginal increase of shear values both at first crack and at failure when the spacing is decreased from one third of shear span to three fourth of effective depth that is from $110 \mathrm{~mm}$ to $87 \mathrm{~mm}$. There is large increase in crack loads when GFRP flats with different spacing was used. Also the percentage increase in ultimate shear is $120 \%$ for $87 \mathrm{~mm}$ spacing of flats and $108 \%$ when $110 \mathrm{~mm}$ spacing was adopted.

\subsection{Comparison of Deflections of Beams}

In experimental work it is observed that compared to control specimens where in no shear reinforcement was used in shear test zone, at load of $20 \mathrm{kN}$, the deflections are decreased by $84 \%$ in the case of beams with two legged stirrups of silica coated GFRP bars at $100 \mathrm{~mm}$ spacing in shear test zone while it is $80 \%$ decrease when the stirrup spacing is decreased to $87 \mathrm{~mm}$. At the load of $25 \mathrm{kN}$ where in the control specimens failed, there is increase of deflections by $76 \%$ in the case of beams with two legged stirrups of silica coated GFRP bars at $100 \mathrm{~mm}$ spacing in shear test zone while it is $54 \%$ increase when the stirrup spacing is decreased to $87 \mathrm{~mm}$.

In the same phase when the comparisons are made at the ultimate failure loads, there is increase of deflections by $76 \%$ in the case of beams with two legged stirrups of silica coated GFRP bars $100 \mathrm{~mm}$ spacing in shear test zone while it is $54 \%$ increase when the stirrup spacing is decreased to $87 \mathrm{~mm}$.

\subsection{Comparison of Tensile Strains of Beams in Test Zone}

It is observed that compared to control specimens (A series) where no shear reinforcement was used in shear test zone, at a load of $10 \mathrm{kN}$, the tensile strains are decreased by $21 \%$ in the case of beams (B series) with two legged stirrups of silica coated GFRP bars at $110 \mathrm{~mm}$ spacing in shear test zone while it is $26 \%$ decrease when the stirrup spacing is decreased to $87 \mathrm{~mm}$ (C series). At a load of $20 \mathrm{kN}$ there is decrease of strains by $23 \%$ in the case of beams with two legged stirrups of silica coated GFRP bars at $110 \mathrm{~mm}$ spacing in shear test zone while it is $29 \%$ decrease when the stirrup spacing is decreased to $87 \mathrm{~mm}$.

In the same phase when the comparisons are made at the ultimate failure loads, there is decrease of strains by $10 \%$ and $15 \%$ in respect of beams of $\mathrm{B}$ and $\mathrm{C}$ series.

\subsection{Comparison of Compressive Strains of}

\section{Beams in Test Zone}

Similar comparisons of compressive strains in test zone are made with control specimen (A series). At $10 \mathrm{kN}$ load the compressive strains are decreased by $22 \%$ and $29 \%$ in the case of B and C series respectively. The values are $23 \%$ and $26 \%$ decrease at 20 $\mathrm{kN}$ load and finally at failure load the decrease of strains are $10 \%$ and $18 \%$ respectively.

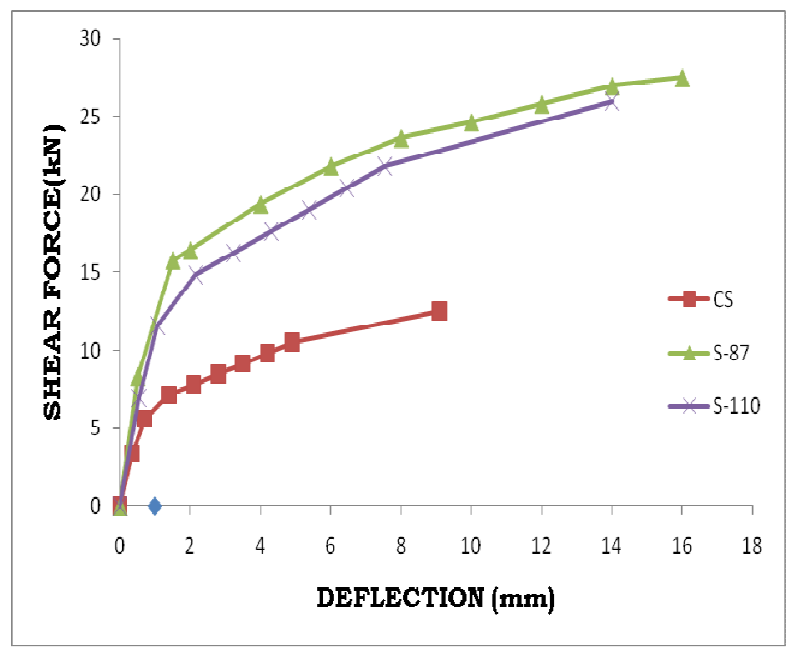

Fig.6.1.Shear Force Vs Deflection At Centre In Beams (a/d $=0.33, \mathrm{p}=1.69$ ) 


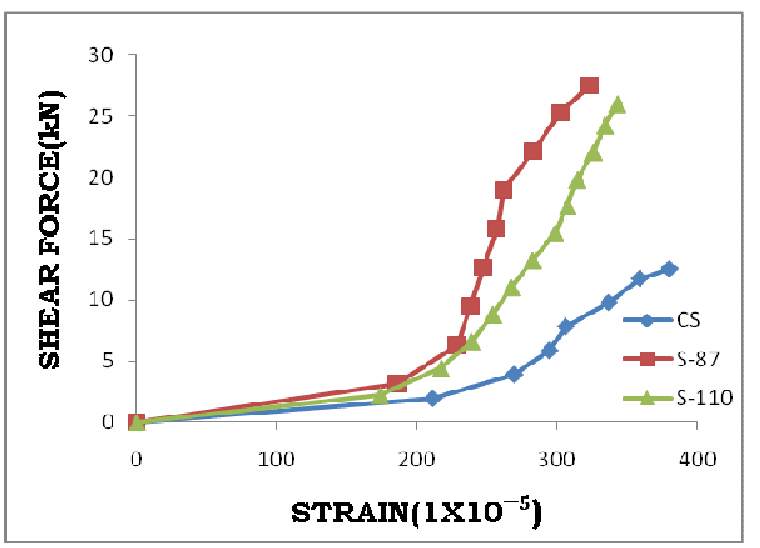

Fig.6.2.Shear Force Vs Tensile Strain in Shear Zone in Beams $(\mathrm{a} / \mathrm{d}=2.81 ; \mathrm{P}=1.7)$

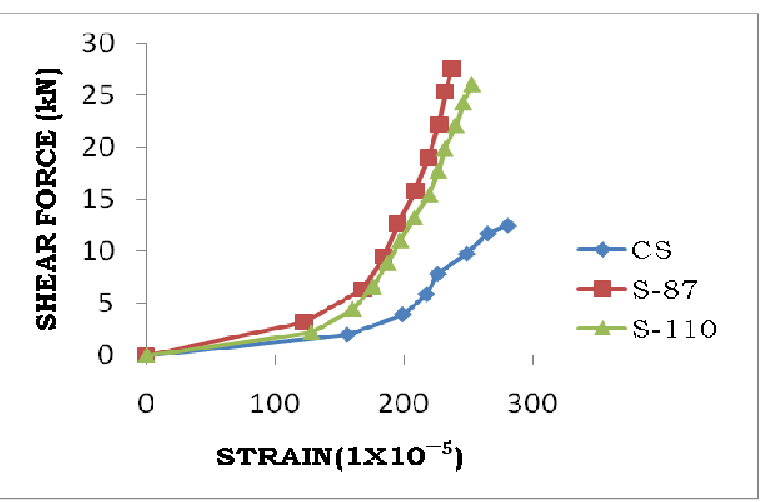

Fig.6.3. Shere Force Vs Compressive Strain In Shear Zone Beams $(\mathrm{a} / \mathrm{d}=2.81 ; \mathrm{p}=1.7)$

\section{CONCLUSIONS}

The following conclusions were arrived based on the experimental investigations and test results:

1. The beams with silica coated GFRP bars and Flats as shear reinforcement, have shown failure at loads higher than the theoretical failure loads. This clearly indicates the improved bond of silica coated GFRP bars with concrete.

2. Beams with GFRP reinforcement, both plain and silica coated have shown higher deflections compared to that of controlled beams with HYSD bars thus indicating improved ductility of GFRP-concrete composite

3. It was observed that the failure of all the beams was not sudden, though the failure of GFRP bars and flats was sudden and associated with splintering of fibers in tension.

4. Also the ratio of Ultimate shear to shear at first crack indicates that the beams with GFRP shear reinforcement exhibit fairly good ductility
5. Further the percentage of variation between the actual ultimate loads verses the theoretical failure loads ranges from 36 to60.

6. The strength of the composites, flats or bars depends up on the fibre orientation and fibre to matrix ratio; higher the fiber content, higher the tensile strength.

7. Also the ratio $\mathrm{Pu} / \mathrm{Pfcr}$ indicates that the beams with GFRP shear reinforcement exhibit fairly good ductility.

8. Further the percentage of variation between the actual ultimate loads verses the theoretical failure loads ranges from 34 to 60.

\section{REFERENCES}

[1] Alexander Placas; and Paul E. Regan, 1971, "Shear failure of reinforced concrete beams," ACI Journal, Title No.68-67, Oct.1971, pp.763-772. Aurelio Muttoni; and Migul Fernandes Rliz,2008, "shear strength of members without transverse reinforcement as function of critical shear crack width," $A C I$ Structural Journal, V.105, No.2, March - April, 2008.

[2] Anil K. Patnaik, Ramakrishna Puli, “ Preliminary Studies on the Use of Basalt FRP for Strengthen Reinforced concrete beams" Proceedings of ICFRC International Conference on Fibre Composites, HighPerformance Concrete and Smart Materials, 8-10 January, 2004, Chennai, India pp 375-385.

[3] Abhijit Mukherjee and S.J. Arwikar, "Performance of Glass Fiber-Reinforced Polymer Reinforcing Bars in Tropical Environments- Part I : Structural Scale Tests", A C I Structural Journal, October 2005, pp 745-753

[4] Braun, J.; and Eskridge, M., 2004, "Concrete Reinforced with Glass Fiber Bars: Innovative and CostEffective Solutions," Proceedings of ICFRC International Conference on Fiber Composites, High Performance Concretes and Smart Materials, January 8-10, 2004,pp. 337-351, Chennai, India.

[5] Biswarup Saikia, Anantha Ramaswamy, "A study on Flexural performance of beams reinforced with GFRP Bars", Proceedings of ICFRC Conference,Chennai, pp 465-474.

[6] Christos G. Papakonstantinou, Micheal F. Petrou, and KenHarries. "Fatigue Behaviour of RC beams strengthendd with GFRP Sheets".Journal of Composite for consturuction, Nov, 2001, pp 246-253. 